\title{
A moda como objeto de informação: o caso do Movimento Feminista Punk Riot Grrrl
}

\section{Fashion as an information object: the case of the punk feminist movement Riot Grrrl}

\author{
Kedma Lima de Castro ${ }^{1}$, Jetur Lima de Castro $^{2}$, Alessandra Nunes de Oliveira ${ }^{2}$ \\ ${ }^{1}$ Universidade da Amazônia - UNAMA, Brasil \\ ${ }^{2}$ Universidade Federal do Pará - UFPA, Brasil
}

Autor para correspondência/Mail to: Jetur Lima de Castro jetur.er@gmail.com

Recebido/Submitted: 12 Jun. 2015; Aceito/Approved:04 Ago. 2015

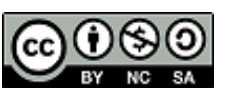
Copyright (c) 2015 Castro, Castro \& Oliveira. Todo o conteúdo da Revista (incluindo-se instruções, política editorial e modelos) está sob uma
licença Creative Commons Atribuição-NãoComercial-Compartilhalgual 3.0 Não Adaptada. Ao serem publicados por esta Revista, os arti-
gos são de livre uso em ambientes educacionais, de pesquisa e não comerciais, com atribuição de autoria obrigatória. Mais informações em

\begin{abstract}
Resumo
Introdução: Ao se considerar que a moda pode ser entendida como objeto de informação, o objetivo do trabalho é apresentar as características de indumentária e de comportamento do movimento feminista punk Riot Grrrl como constituintes espaço de discurso e de linguagem e, portanto, no escopo de investigações na área de Ciência de Informação e Biblioteconomia.

Método: Trata-se de pesquisa exploratória de base bibliográfica e documental.

Resultados: apresenta-se o momento histórico do movimento punk Riot Grrrl no contexto punk, analisando-se a temática do feminismo, a discussão de gênero e suas relações com a moda entendendo-se a indumentária das riots grrrls como forma de protesto e discurso político em seu contexto histórico-social.

Conclusão: as releituras visuais do movimento feminista punk, sustentadas em seus ideários radicais e seu impacto no universo da moda, revelam a representatividade da indumentária e do comportamento como formas emancipatórias no social, configurando-se como espaços de discurso e, portanto, de informação.
\end{abstract}

Palavras-chave: Movimento punk; Discurso de Gênero; Moda; Moda como informação; Feminismo

\begin{abstract}
Introduction: In considering the issue of fashion as an object of information, the study aims to present the behavior and attire characteristics of the punk feminist movement Riot Grrrl as constituents of a singular language and discourse space and, therefore, subject to further investigations by the area of Library and Information Science.

Method: This is an exploratory research of bibliographic and documentary base.

Results: it presents the historical scene of punk feminist movement Riot Grrrl within the punk background, analyzing the theme of feminism, the discussion of gender and its relationship with the overall fashion context. It was revealed that the Riot Grrrrls' behavior and attire act as way of gender and political dissent.

Conclusion: the visual reinterpretation of a punk feminist movement supported in their radical ideologies and their impact on the fashion world shows the representative nature of attire and behavior as emancipatory forms in the social, configured as discourse spaces and, therefore, as an information attribute.
\end{abstract}

Keywords: Punk movement; Gender discourse; Fashion; Fashion as information; Feminism

\section{INTRODUÇÃO}

Desde os primórdios da civilização, diversas formas de comunicação - tais como os desenhos, signos, a escrita e outras manifestações - se desenvolveram com o objetivo de informar e estimular a aprendizagem. É perceptível nesta trajetória que cada indivíduo passou a encontrar maneiras de transpor sua mensagem de forma que esta seja aceita por aqueles que se identificam com ela.

M. Oliveira (2005, p. 19) ressalta que a informação “[...] é um fenômeno tão amplo que abrange todos os aspectos da vida em sociedade" e, segundo Miranda (2006, p. 103), "grupos distintos de pessoas têm diferentes necessidades e hábitos de busca de informação, bem como estilos diferentes de processar a informação". Estas abordagens compreendem que a informação está inserida em diferentes suportes e que há diversas formas de utilizá-la.

A moda - como aspecto da vida social - pode ser considerada uma manifestação e uma representação informativa e, neste contexto, os movimentos sociais e de gênero podem utilizar a moda como forma de evidenciar questionamentos na sociedade. A identidade feminina pode ser compreendida no campo social como um fenômeno de linguagem, veiculando valores individuais, sociais e políticos, no qual o discurso feminista se utiliza do conceito de "gênero" para desnaturalizar os papéis e identidades atribuídas às mulheres. 
Por exemplo, no contexto da indumentária, o movimento feminista se insurgiu frente ao estereótipo da vestimenta "conservadora", no qual o ideal de gênero é voltado à mulher mais recatada, dona do lar, aprisionada nas suas roupas, que refletem um papel de submissão, restrição e obediência (Joaquim \& Mesquita, 2012).

Mais especificamente, o movimento feminista punk Riot Grrrl - que surge em 1990 nos Estados Unidos relacionou a moda com a discussão de gênero, efetivando rupturas no modelo normativo da mulher como "dona de um lar”, a partir da exaltação de suas "virtudes naturais” e buscando avançar sobre a barreira emancipatória feminina.

O movimento Riot Grrrl relaciona-se não apenas com a moda, enquanto abordagem da indumentária, mas também por sua linha de referência de libertação, apoiada em questionamentos sobre o que é imposto pela sociedade, e na busca de uma identidade própria e emancipada da mulher. Essa rebeldia manifestou-se em uma espécie de "popularização na maneira de se vestir", de modo que a semelhança da roupa impedia que se classificassem as diferentes classes sociais, incluídas aí nas discussões de gênero, pois como afirmam Joaquim e Mesquita (2012, p 99), “(...) a moda contribuiu para redefinir identidades sociais, [desconfigurando] algumas das fronteiras simbólicas entre o masculino e o feminino, sendo motor e reflexo das mudanças da condição feminina (...)".

Dado este contexto, o objetivo do estudo é apresentar as relações do Movimento Punk e, mais especificamente, o Riot Grrrl com a moda, e esta como objeto de informação. Discute-se o momento histórico deste movimento dentro do contexto punk, analisando-se temática do feminismo, a discussão de gênero e as reações que se estabelecem na moda considerando-se a indumentária das Riot Girrrls nos anos 1990. Buscou-se verificar, igualmente, a relação do Movimento Riot Girrrls com aquele contexto histórico sociopolítico, observando-se a indumentária como forma de protesto e, portanto, de discurso daquela comunidade.

Trata-se de uma pesquisa exploratória, de base bibliográfica e documental, fundamentada em ideias especialmente Ribeiro, Costa, e Santiago (2012), Coloni e Fernandes (2005), Bivar (1982) e Habermas (1987), sem dispensar as opiniões de outros pensadores sobre o assunto abordado no trabalho. Gil (2002) afirma que a pesquisa exploratória proporciona maior familiaridade com o problema ao explicitá-lo e pode envolver tanto o levantamento bibliográfico como entrevistas com pessoas experientes no problema pesquisado. A pesquisa exploratória apoia-se em determinados princípios bastante difundidos: 1) a aprendizagem melhor se realiza quando parte do conhecido; 2) deve-se buscar sempre ampliar o conhecimento e 3) esperar respostas racionais pressupõe formulação de perguntas também racionais (Piovesan, 1968).

Em outras palavras, o estudo exploratório, tem por objetivo conhecer a variável de estudo tal como se apresenta, seu real significado e o contexto onde se insere. Pressupõe-se que o comportamento humano é mais bem compreendido no contexto social onde ocorrem (Queiróz, 1992). Assim, buscou-se maior conhecimento sobre o problema para torná-lo mais explícito, e, assim “ [...]aumentar a familiaridade do pesquisador com um ambiente, fato ou fenômeno, para a realização de uma pesquisa futura mais precisa, ou modificar e clarificar conceitos" (Marconi \& Lakatos, 2006, p. 171).

A investigação oferece releituras visuais do movimento feminista punk em geral e das Riot Grrrls em particular, e de seus ideários radicais no contexto do universo da moda, na qual a indumentária pode ser discutida como forma emancipada no social e entendida como um tipo de discurso representativo.

\section{O MOVIMENTO PUNK}

Surgido na década de 1970 nos Estados Unidos e na Inglaterra, o Movimento Punk foi um fenômeno social marcado por sua forte ideologia de contestação do sistema capitalista, sendo identificado como um movimento de contracultura.

O movimento foi questionador em seu contexto histórico e social, pois a Inglaterra estava em plena desordem social, com aumento do desemprego e, consequentemente, da violência. Com a diminuição da educação para as classes baixas, um grupo de jovens insatisfeitos com esta situação percebeu que já não havia um futuro e encontraram na música a sua expressão, como forma de revolta contra as condições em que viviam. O punk motivou e atraiu,

[...] a juventude identificada com o ritmo, às ideias anarquistas e revolucionarias das letras que tratam de problemas sociais como desemprego, as guerras, a violência, a contestação da ordem burguesa, o papel do Estado, além de temas do cotidiano como relacionamentos, drogas, diversão e outras situações vivenciadas pela juventude (Ribeiro et al., 2012, p. 1).

A juventude que representava o Movimento Punk era marginalizada e desaprovada pela sociedade por seus ideais de rebeldia e por suas revoltas contra o sistema, pois ironizava a sociedade com suas músicas sarcásticas de acordo com a realidade socioeconômica dos jovens. 
Tendo como proposta a transgressão à ordem, ao sistema, à liberdade no consumo das drogas, e o total repúdio ao consumismo, a palavra punk - como uma espécie de gíria da língua inglesa - remete ao significado de sujeira, imoralidade, desrespeito à ordem, cuja abordagem é identificada com o anarquismo e incorporando à estética do antifascismo e do antimilitarismo (Weber, Gallina, \& Ronsini, 2004, p. 170).

O movimento abrangeu tanto os meios sociopolíticos, como da arte, cultura e música, pois naquele momento o rock'n roll carecia de inovação e os jovens precisavam de diversão e algo que rompesse com a monotonia. O conceito de punk começou a surgir com a chegada da Banda Ramones ${ }^{1}$ que revolucionou o então chamado punk rock, com contagiantes músicas de três minutos e letras de questões cotidianas, as quais foram rapidamente aceitas por parte do público (Souza \& Fonseca, 2009).

Nesse mesmo contexto surgiram os fanzines ${ }^{2}$, carregando a ideia do "faça você mesmo" (do it yourself, lema do punk, que tratava de produções totalmente independentes, organizando seus próprios grupos musicais. Artistas e bandas produziam de forma autônoma desde suas próprias roupas até seus discos, em uma guerra dos jovens contra o sistema, utilizando os sons e as ideias punks como armas contra o capitalismo e o consumismo.

A banda Sex Pistols foi uma das grandes precursoras do movimento punk, pois trazia em suas letras a revolução da juventude, propostas anarquistas, contra toda forma de opressão e poder. Seu primeiro sucesso, Anarchy in the U.K. (Anarquia no Reino Unido) de 1976, expõe as finalidades do movimento:

Eu sou um anticristo, eu sou um anarquista. Não sei o que eu quero. Mas eu sei como chegar La. Eu quero destruir quem passa por mim. Porque eu quero ser anarquia - e não um cão. Eu quero ser a Anarquia - entenda o que eu digo. E eu quero ser um Anarquista - me defender e destruir (SEX PISTOLS... 1977) $)^{3}$

A partir da década de 1980, o estilo se tornou mais notório, pois passou a ganhar destaque na mídia, sendo difundido por todo o mundo e relacionado à má reputação dos seus integrantes e ao vandalismo. Embora tenha ganhado notoriedade mundial, o estilo punk se transformou em produto de consumo, abandonando suas bases originais e, ao visar fins lucrativos, tornou-se superficial, Para Iori, Menegazzi, Moraes, e Richetti (2006) a sociedade industrial, a cultura massificada e os interesses voltados à globalização degradaram toda a essência do punk que, “(...) de movimento contestador, furioso e agressivo, [...] tornou-se estilo inofensivo, passivo e padronizado”.

\section{O Punk e suas vertentes no Brasil}

De acordo com Bivar (1982), o Movimento Punk, vindo da Inglaterra, se alastrou pelo mundo. No Brasil, segundo o documentário “Botinada! A origem do punk no Brasil !” (Produzido por Gastão Moreira, em 2011) o punk rock chegou na década de 1980 com os vinis trazidos de Londres pela juventude da classe alta de Brasília que estudaram na Inglaterra. No então contexto histórico da ditadura militar, os jovens eram atraídos pelos ideais anarquistas.

Em 1990 ocorreram mudanças no movimento no Brasil - diferentemente dos Estados Unidos e Inglaterra - e o punk rock se dividiu em outras vertentes, tais como o Hardcore, representado por bandas de punk-hc tais como Ratos de Porão, Inocentes, Cólera, Garotos Podres, Olho Seco, e Lixomania. O hardcore é considerado uma segunda geração do punk como expõe o documentário "Botinada! A origem do punk no Brasil”.

Apesar dos diferentes resultados estéticos de suas obras, muitos reivindicam o termo hardcore para garantir uma inserção cultural ou por um laço de identidade ou de pertencimento à cena punk. Assim, bandas tais como Dominatrix, a Skizitas, a Zona X, e a Banda sem nome, manifestam um discurso alternativo ante a ordem e os valores estabelecidos, instituindo aí, mais que uma prática cultural, uma manifestação política ${ }^{5}$.

De acordo com Bivar (1982) em São Paulo o movimento manifestava sua rebeldia a partir do "uniforme" (tudo preto: blusão de couro, o jeans, a camiseta, o tênis ou o coturno, os botões com emblemas dos grupos), do comportamento agressivo, e da música contestadora e acelerada, seca e ensurdecedora. Os punks paulistanos

\footnotetext{
${ }^{1}$ Ramones foi uma banda norte-americana de punk rock formada em Forest Hills, Nova York, no ano de 1974. É considerada como precursora do estilo e uma das bandas mais influentes e importantes da história do rock - http://ramones.com/

${ }^{2}$ [...] Fanzine é a junção das palavras fan (de fã, em português) com magazine (revista, em inglês). Fanzine = uma revista feita pelo fã e para o fã. (BIVAR, 1982, p.51)

${ }^{3}$ I'm an antichrist, I'm an anarchist. Don't know what I want. But I know how to get it. I wanna destroy the passerby. Cause I want to be anarchy. No dog's body (...) And I wanna be an anarchist. I get pissed, destroy. SEX PISTOLS. (Anarchy in the U.K) Never Mind the Bollocks, Here's the Sex Pistols. Londres: Warner Bros record, 1977. 1 disco sonoro (37 min), 33 1/3 RPM, estéreo.

${ }^{4}$ Documentário sobre opunk no Brasil, dirigido por Gastão Moreira, "Botinada: A Origem do Punk no Brasil" apresenta a história do movimento punk, que se formou em diversas regiões do Brasil, principalmente São Paulo e Brasília, no começo da década de 1980, influenciado inicialmente pelos movimentos surgidos na Inglaterra e Estados Unidos durante o final da década de 1970. Este documentário foi construído através de diversos relatos daqueles que participaram ativamente do movimento e o vivenciaram desde o seu início. Figuras que marcaram a cena musical punk paulista e brasiliense, além de outros que frequentaram os locais de encontro da juventude punk dão seu depoimento sobre este movimento de natureza controversa e rebelde, tentando definir seu objetivo e as suas origens, mostrando as suas peculiaridades em relação aos exemplos estrangeiros. Disponível em: https://www.youtube.com/watch?v=221SR-04n98

${ }^{5}$ CONFRONTO. Insurreição. São Paulo: Liberation, 2001. 1 CD
} 
tinham entre 18 a 27 anos em média e muitos eram do proletariado. Com o ressurgimento do movimento, foi lançado o primeiro disco independente do movimento Punk Rock no Brasil, O Grito Suburbano, das bandas Cólera, Inocentes e Olho Seco, o que entusiasmou a juventude do movimento.

Os punks Paulistanos começaram a editar seus fanzines, divulgando o movimento com manifestos e comentando sobre o social punk e os jovens reformistas que buscam em suas atitudes se rebelarem contra as opressões. O hardcore era retratado como cotidiano vivido pela juventude paulistana e o som constituiu-se como instrumento de incentivo à luta. Contudo, o movimento punk brasileiro ainda se mostrava fechado para os ideais libertários feministas, ainda que o Riot Grrrl estivesse se formando no cenário americano.

\section{O MOVIMENTO RIOT GRRRL}

O Riot Grrrl é o movimento de cultura juvenil, que abrange a música, o feminismo, a cultura, a literatura, o cinema e a política. Surgiu em 1990 nos Estados Unidos, formado por um grupo de garotas que contestaram as relações de gênero dentro do movimento punk rock e os papéis sociais reservados às mulheres. $\mathrm{O}$ contexto do Riot Grrrl engloba o movimento punk rock, expandindo-se globalmente de forma acelerada e com o surgimento de grupos articulados. Conforme Melo (2006, p. 1),

O feminismo Riot Grrrl partiu num primeiro momento de uma inquietação políticas: numa conjuntura em que se propaga o discurso de que "as mulheres conquistaram seu espaço" e de que o feminismo é algo ultrapassado, nos parece oportuno de que forma essas jovens feministas tem se constituído, remodelando e apropriando o feminismo pautado nas experiências e visão de mundo da juventude.

Na cena punk e hardcore as garotas começavam a contestar o domínio masculino e o androcentrismo e passaram a dar voz à manifestação feminista. A proposta do movimento Riot Grrrl era fazer com que as garotas participassem e se apropriassem do cenário de discussão dos papéis sociais reservados as mulheres, defendendo assim novas bandeiras do feminismo. A propagação das ideias das Riot Grrrls também se fazia pelas zines ou fanzines, cheias de colagens e textos produzidos pelas próprias garotas.

A zine Revolution Girl Style Now foi criada pelas punk feministas Ketheleen Hanna e Alison Wolfe - ambas da cidade de Olympia/USA - já conhecidas pelas várias manifestações pelo fim da violência contra a mulher, e a revolta pela ausência das garotas na cena punk-hardcore. A dupla criou outra zine chamada Bikini Kill, junto com Katie Wilcox, e logo o movimento conquistou visibilidade e passou a organizar bandas só de mulheres. Ketheleen Hanna é reconhecida como a difusora, pioneira e ícone da cena riot. O termo riot

[...] aparece pela primeira vez em outro zine de Tobi Vail - baterista do Bikini Kill - e possui como significado literal 'garotas amotinadas' ou 'motim de garotas'. O grrrl é onomatopeia usada para representar um rosnado de raiva. Uma fúria do movimento dando a entender que são garotas furiosas (Ribeiro et al., 2012, p. 7)

Hanna e Wolfe apresentavam elementos do feminismo como estilo de vida para a cena hardcore influenciando outras garotas que passaram a serem difusoras do feminismo riot, tais como June Jordan e Bell Hooks. Estas escritoras feministas têm um papel importante na disseminação do movimento riot principalmente pelo rompimento com as políticas excludentes voltadas à comunidade negra, questionando o racismo e vinculando as bandas riot em suas ações de movimentos sociais. Um elemento de difusão do movimento riot foi o Ladyfest, festival que começou na cidade de Olympia, Estados Unidos, e depois se espalhou por vários países. Consiste em um festival independente e de participação voluntária que reúne bandas, oficinas, debates, músicas, expressões do feminismo, vegetarianismo/veganismo, com todas essas ações voltadas para as relações de gênero (Ribeiro et al., 2012).

No Brasil, Elisa Gargiulo se caracteriza como maior ícone de expressão do Movimento. Em 1995 - com o punk e hardcore já presentes nos subúrbios brasileiros, bandas como Bikini Kill e Bratmobile chegam aos ouvidos das brasileiras de faixa etária entre treze a vinte anos - e estudantes de classe média - que se identificavam com o som e as letras (Leite, 2012, p. 24).

Naquele momento havia mais homens na cena punk, criando assim um ambiente hostil e intimidador para as garotas. Este cenário mudou com a criação da banda Dominatrix - primeira banda punk feminista brasileira criada pelas irmãs Elisa e Isabella Gargiulo, que usavam a internet e mídias, tais como o Orkut e o MSN/Messenger, como elementos de propagação e divulgação das suas músicas, letras e shows.

Depois do surgimento da Dominatrix, outras bandas começaram a se difundir dentro do movimento riot dentre eles estão: Kaos Klitoriano, Bulimia, No Steriotypes, Cosmogonia, As Mercenárias e Menstruação Anárquica, e outras vertentes, tais como o Queercore - que tem ligações e embasamento com o movimento Lésbicas, Gays, Bissexuais e Travestis (LGBT) - e a Straight Edge, cuja ideologia - dentro do punk - é voltada à defesa total de álcool, drogas e veganismo ${ }^{6}$.

\footnotetext{
${ }^{6}$ Modo de vida que busca eliminar toda forma de exploração de animais, não apenas na dieta, mas no vestuário, em testes e na composição de produtos, no trabalho, no entretenimento e no comércio (Monteiro \& Garcia, 2013, p 6)
} 
Conforme Ribeiro et al. (2012), as atitudes radicais tanto de estilo e comportamento são características inerentes às garotas riots. A cultura Riot Grrrl é aberta a novos costumes devido ao seu ambiente libertário, explicitado nas letras, nas músicas e nas zines. Todas as garotas são incentivadas e convidadas a produzirem e se expressarem, estimulando-se a rebeldia e a libertação do corpo da mulher a partir do trabalho em produções independentes. O Movimento contesta o ideal de beleza estimulado por revistas teens ${ }^{7}$, como dicas para emagrecer, para se tornar uma jovem bonita e para atrair rapazes. As garotas riot contestavam toda e qualquer opressão do corpo, pois se vestiam conforme gostavam (Arruda, 2011)).

Algumas riot usavam piercing, tatuagens, utilizando seu corpo como discurso político. Muitas delas não se maquilavam e assumiam vestimentas masculinas, tais como bermudas e bonés e, algumas das letras das bandas do Movimento expõem a desconstrução de gênero, tais como:

Lutando pra ser mais bonitinha. Lutando pra ser o que a TV mostrou. Pensar não vai te deixar com rugas. Saia da vitrine à espera de seu par. Ser mulher não é ser uma boneca em carros à enfeitar. Como a publicidade insiste em mostrar. Use a cabeça que você tem. Não aceite ser objeto de ninguém. Não se submeta! Questione sempre neste mundo feito só pra homens. (BULIMIA, 2008) ${ }^{8}$

O riot é a disseminação de ideias e ideais, buscando uma desconstrução da sociedade por meio da crítica do gênero e da propagação de novas formas de fazer política. Um exemplo de como as riots faziam do seu corpo um discurso político, no qual proclamam a liberdade de suas ações e questionando o Estado na repressão e opressão do corpo da mulher, pode ser verificada na letra da música Meu Corpo é Meu da banda Dominatrix: "P*ta é aquela que se dá para quem se dá sem o seu aval misógino, mas meu corpo é meu"9

Assim, acompanhando o discurso presente nas letras das bandas, a moda punk pode ser explorada como objeto de informação com significado semântico.

\section{A MODA PUNK ENQUANTO DISCURSO E COMO OBJETO DE INFORMAÇÃO}

A informação, em um dos sentidos dados pela Biblioteconomia e pela Ciência da Informação, tem forte caráter social (Ortega, 2006). O “campo simbólico" da informação na estrutura social se desenha como uma questão emancipatória na luta pelos direitos iguais e pela liberdade, o que implica na democratização da informação e do direito de ser informado.

Conforme A. C. Oliveira e Castilho (2008), o corpo pode ser considerado como um índice das mudanças em curso na sociedade, uma vez que absorve e reflete as informações do ambiente no qual está inserido. O corpo é dependente do meio físico e dos contatos que estabelece, e nos quais se reconhecem padrões de comportamento, traços de uma cultura e diálogos sócio históricos, o que é respaldado pelo caráter comunicacional dos seres humanos.

Neste sentido, a análise crítica proposta por Habermas (1987) vem ao encontro das discussões que podem envolver a Ciência da Informação e a Biblioteconomia e o campo da Moda. Para o autor, o agir comunicativo se configura em atividades voltadas à compreensão, via o diálogo compartilhado. A importância dessa aproximação é a teoria crítica vista por Jürgen Habermas que parte dos pressupostos hermenêuticos para compreender a relação do sujeito com o social, principalmente a partir de uma emancipação ${ }^{10}$. Para o pensador,

[a] compreensão hermenêutica é a interpretação de textos a partir do conhecimento de textos já compreendidos; ela conduz a novos processos de formação a partir do horizonte de processos de formação já realizados; trata-se de um novo processo de socialização, que se articula com uma socialização já percorrida, na medida em que ela se apropria da tradição, ela dá prosseguimento à tradição (Habermas, 1987, p. 237-38).

A compreensão hermenêutica tem, de acordo com sua estrutura, o objetivo de assegurar no seio das tradições culturais, uma autoconcepção dos indivíduos e dos grupos, susceptível de orientar a ação e o entendimento recíproco de diferentes grupos e indivíduos. Ela possibilita a forma de um consenso espontâneo e o tipo da intersubjetividade indireta; dela depende a atividade pertinente à comunicação (Habermas, 1987, p. 186). Assim, a hermenêutica proposta por Habermas evoca o caráter interpretativo da ação crítica e analítica com base nos métodos de investigação do conhecimento. No campo da moda, o vestuário atua como um conjunto de signos, que enfatiza a função de definição do ser social, ou seja, não se limita simplesmente a uma função de proteção, pudor ou adereço, mas se impõe como elemento de diferenciação, tornando o vestir-se um ato significativo e de informação (Brandes \& Souza, 2012).

\footnotetext{
${ }^{7}$ Abreviatura da palavra teenager que em língua portuguesa significa adolescentes.

${ }^{8}$ BULIMIA. Publicidade: se julgar incapaz foi o maior erro que cometeu. São Paulo: Tratore, 2005.

${ }^{9}$ DOMINATRIX. Quem defende pra calar. São Paulo: Dykon Records, 2009.

${ }^{10}$ Autorreflexão é percepção sensível e emancipação, compreensão imperativa e libertação da dependência dogmática numa mesma experiência (Habermas, 1987, p 228)
} 
Neira (2008) discute os conceitos de Roland Barthes relativos às semelhanças estruturais entre a moda e a linguagem, na qual a escolha pessoal de cada indivíduo (fala como traje) carrega uma potencialidade expressiva, ainda que não tome "a moda como uma bandeira idealista de qualquer discurso [...]" (Barthes, 2004, apud Neira, 2008, p. 5). Em um discurso de um movimento social, que em seu fundamento não visava "ser a moda", mas o que se veste se concretiza como desejos e necessidades, a construção dos trajes e modos de vestir sofrem modificações; o primeiro território onde isto se explicita é o próprio corpo, pois sobre ele fazem-se as marcas e os símbolos, expressam-se os gestos e mudam-se os adereços (A. C. Oliveira \& Castilho, 2008).

Neste sentido, ao se buscar compreender a moda no contexto dos objetos informação procura-se não somente entendê-la como um fenômeno ou modelo estético, mas sim no estado transcendente, que apresentam diálogos críticos na conjugação do autoritarismo e liberdade, ao se enfatizar a teoria crítica do corpo e este corpo como emancipação e como luta contra o consenso (A. C. Oliveira \& Castilho, 2008, p 72-73). Para Castilho (2004) (apud Brandes \& Souza, 2012, p. 120) "a moda pode ser considerada um ato de presença do próprio sujeito no mundo". Para as autoras a moda filia o indivíduo a “...determinados discursos sociais que expressam sua visão de mundo. De certa forma, todas as sociedades vestem o corpo, seja com pinturas, tatuagens, escarificações, perfumes ou roupas propriamente ditas, sempre com a intenção de construir seu discurso e significar algo. Ao inserir-se no contexto da cultura corporal, a moda é concebida como um sistema de significações por meio do qual o indivíduo cria valores e interage com o mundo e com o outro" (Brandes \& Souza, 2012, p. 120)

Segundo Brandes e Souza (2012), a "roupa comunica a identidade de quem a veste" e cada indivíduo, ao assumir esta ou aquela aparência, está constituindo parte de sua identidade (Castilho, 2004, apud Brandes \& Souza, 2012). Bivar (1982) discute em seu livro "O que é o Punk" que outros movimentos culturais da cena musical contribuíram para o Movimento punk e atingiram a juventude alterando o seu modo de vestir. Segundo o autor, entre eles estão os beatnicks nos anos de 1950, os hippies nos anos de 1960, e os mods, nos anos de 1950.

Mais especificamente ao movimento hippie, que naquele momento vivenciava a sociedade alternativa - na qual a juventude defendia o amor livre e a não violência - a liberdade do corpo sem repressões, Bivar (1982) destaca a indumentária particular, composta de calças de jeans, pantalonas com boca de sino e, no lugar de camisas e blusas; ambos os sexos usavam batas indianas, introduzindo o estilo unissex.

No mundo da moda punk Vivienne Westwood é considerada a rainha do punk. Nascida em 1941 numa pequena localidade da Inglaterra, explorou o universo feminista libertário em seus desfiles, sendo uma das difusoras da moda punk feminista. Em 1965, já vivendo em Londres, Vivienne conheceu Malcolm McLaren e, juntos, passaram a criar roupas alternativas. Nestas, a estética punk mostrava cabelos espetados e coloridos, roupas velhas que simbolizavam o anticonsumismo; jaquetas com frases de rejeição às injustiças de um estado repressor (Bortholuzzi, 2012). Com o social invadindo o estético, a moda se apropriou do instinto selvagem da juventude, e a "alta moda" já não era mais tendência, e sim o diferente, o estilo individual, o look. Logo, Vivienne tomou para si a 'estética da revolta' 11 .

Com sua primeira loja, Let it Rock, criada em 1971, começou a produzir roupas visando o público mais radical das periferias de Londres, sendo ela mesma totalmente excêntrica, provocadora e irreverente. Criava roupas com ideais políticos, com críticas ao social e temas eróticos. Utilizava, como forma de crítica, muita cor preta, muito vermelho e outras cores fortes; muito couro, correntes e rasgos, camisetas com estampas pornográficas de influência fetichista (Rocha, 2005). Logo no início de sua carreira fazia suas roupas no estilo do it yourself, já que a regra do punk é não existir regras. Para Bortholuzzi,

[...] o movimento punk e o trabalho da estilista Vivienne Westwood, resta claro que os traços desse movimento, mesmo que às vezes mais apagados, estão visivelmente presentes no trabalho dela. Também fica evidente que os indivíduos que pertencem a esse movimento expressam sua revolta e seus ideais a partir da sua indumentária, e que Vivienne tem imensa contribuição nisso (Bortholuzzi, 2012, p 10).

Outros estilistas e outras marcas famosas também se inspiraram na estética punk, desde as grifes mais inovadoras, tais como a Rodarte e a Alexander McQueen. Até as mais clássicas, como Chanel e Givenchy, a exemplo do uso das caveiras, que se tornaram símbolo do estilista brasileiro Alexandre Herchcovitch, os spikes (objetos pontiagudos) invadiram a moda clássica e as caveiras se proliferaram. Apesar do punk se opor ao mundo fashion como movimento, a moda se apropria da estética punk, procurando capturar a rebeldia juvenil.

Uma inspiração anterior que merece destaque é a da estilista Chanel que, em 1915, quebrou a barreira do feminino e masculino, não remodelando o corpo feminino, mas sim o libertando, desprendendo-o, e transmutando a mulher, como forma de protesto. Inovou a estética do seu tempo, desatrelando a imagem da mulher daquela submetida ao uso de roupas opressoras, de cor predominantemente branca, envolta em "frufrus", golas altas e cinturas marcadas pelo sufocante espartilho (Cláudio, 2009).

\footnotetext{
${ }^{11} \mathrm{Na}$ 'estética da revolta', a ação estética é diretamente ação política, quando, por exemplo, é ligada a uma infração, transgressão de leis ou de proibições. Na estética da resistência, a consciência política reflete suas dúvidas artisticamente, sua história, seu possível fracasso, as perguntas não respondidas com as quais todo fazer político se ocupa. Na estética da revolta, a arte participa diretamente de um movimento político (Lehmann, 2014, p. 17)
} 
Para Braga (2004), Chanel inovou a moda ao fazer taileurs de jérsei, uma malha de toque macio e com aspecto elástico e, assim, começou a surgir certo estilo andrógino, o que parecia estar bem de acordo com os tempos, uma vez que a mulher buscava sua emancipação. Além disto, para o autor, o fato das mulheres passarem a ganhar dinheiro contribuiu para essa libertação.

No movimento riot verifica-se uma identidade particular. A maioria dos acessórios usados pelas garotas riot eram pulseiras e cordões de spikes, alfinetes, piercings, maquiagem marcada nos olhos (geralmente preta), meias em arrastão, geralmente rasgadas e coturnos (figura 1).

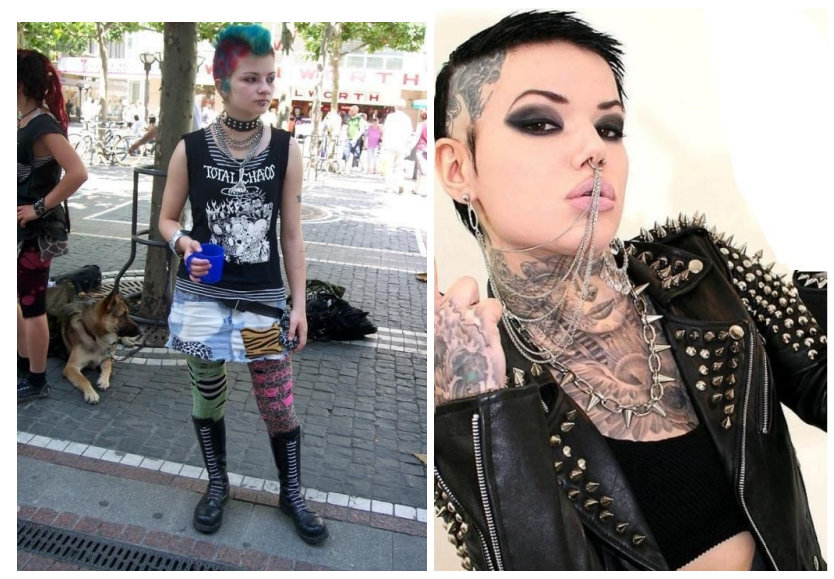

Figura 1. Riot girl: indumentária e acessórios - exemplos.

Fonte: http://free-vector.co/free-vectors/image-punk e http://www.pic2fly.com/Punk-Piercings.html

Ao se pensar em moda punk é necessário lembrar o que sua indumentária traz à tona originalmente, ou seja, a revolta da juventude - focada na estética do belo e do feio, que rompe com a imagem conservadora e com os costumes da sociedade - assim como na crítica do sistema político e tendo no corpo um meio de contestação, manifestação e rebeldia. A vestimenta dos jovens punks é agressiva, incluindo roupas rasgadas e de segunda mão, com elementos como tachas, correntes, alfinetes e seus complementos (cabelo, maquiagem e calçado entre outros).

Segundo Coloni e Fernandes (2005), as garotas punks tendem a exagerar na maquilagem carregando os olhos de preto, vestindo minivestidos, ou apenas uma camisa de homem bem larga, complementada com uma gravata. Vários estilistas de marcas famosas buscam ou buscaram inspirações do movimento punk, trazendo à cena a indumentária juvenil extremista e rebelde, principalmente para as garotas, ainda que os garotos também comprassem

peças de roupas de segunda mão, paletós, calças, camisas, gravatas que eles usavam do jeito que eram encontradas ou dando-lhe um retoque pessoal nelas ou arrancando pedaços aqui e ali e acrescentando manchas, mensagens e símbolos, colocando alfinetes e correntes e até mesmo rasgando as peças mostrando um efeito de que foram resgatadas de uma guerra. Este aspecto visual do movimento punk casou um forte impacto na época onde a Inglaterra vinha de uma imagem de tradição conversadora gerando assim um ataque frontal a sociedade (Coloni \& Fernandes, 2005, p. 126)

Sendo assim, a moda pode exercer um papel de ferramenta ideológica no meio social e cada indivíduo a traduz de um modo diferente, atuando como um meio informacional que gera em todos os indivíduos um conjunto de significados, conceitos e amplitudes diferentes. O punk, por exemplo, usa não só a música como, principalmente, a roupa para provocar e desafiar a ideologia dominante; contestar a política, a distribuição do poder na ordem social, e revelar sua indignação e insatisfação contra o sistema.

Segundo Ciquini (2010, p. 14) “a partir da década de 1990, pipocam butiques nos grandes centros urbanos vendendo acessórios e roupas características dos punks. O que antes era vil e de extremo mau gosto agora é vendido quase como item indispensável no guarda-roupa”. As impressões do vestuário punk feminista propõem que os indivíduos incorporem o espírito do estilo pelas peças de roupa vestem, embora, o autor faça algumas ponderações considerando as pessoas que usam tais peças tenham se apropriado do seu contexto histórico e de suas questões simbólicas.

Essas novas formas de ver o punk abriram o Movimento para todas as pessoas, convidando-as a adotá-lo como estilo, ainda que não necessariamente se proponha a que elas se identifiquem com a ideologia do Movimento. A moda tende a flertar com elementos da rebeldia, a exemplo da coleção exposta por Alexander McQueen em Paris para o verão de 2014. Percebe-se que McQueen, em suas releituras, resgata muitos elementos do punk, como o couro, o spike, os rebites. A Rainha do Punk, Vivienne Westwood, por sua vez, com a coleção de Verão 2012 em Paris, continua a trazer elementos da cultura punk associados à moda contemporânea, privilegiando o visual chocante e extravagante das peças rasgadas (figura 2). 


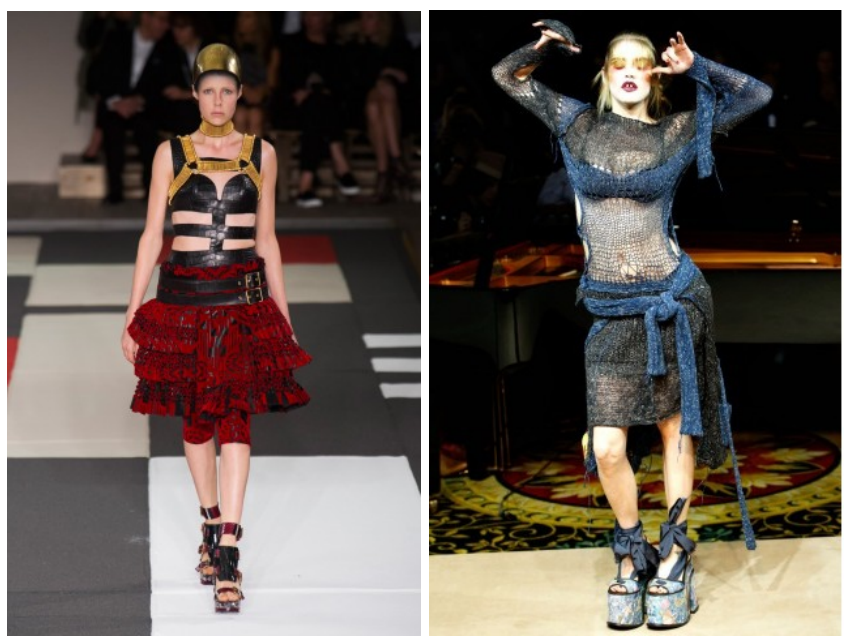

Figura 2. (esquerda) coleção com elementos do movimento punk: couro e fivelas - (direita) Vivienne e sua coleção sobre rasgados: Verão 2012, Paris.

Fonte: http://ffw.com.br/desfiles/paris/verao-2014-rtw/alexander-mcqueen/810582/colecao/1/.

Fonte: http://ffw.com.br/desfiles/paris/verao-2012-rtw/vivienne-westwood/3761/

As fast fashions/moda rápida (grandes marcas/magazines de produção), tais como a internacional C\&A e a brasileira Riachuelo, tem se apropriado do que foi exibido nas passarelas para seus editoriais e, em suas novas coleções apresentam as influências de rebeldia punk. Passam a propor para um grupo mais amplo de jovens outras formas ver o "novo punk". O editorial da C\&A para sua coleção de 2014 foi inspirado na rebeldia punk (Rocha, 2005) (figura 3).
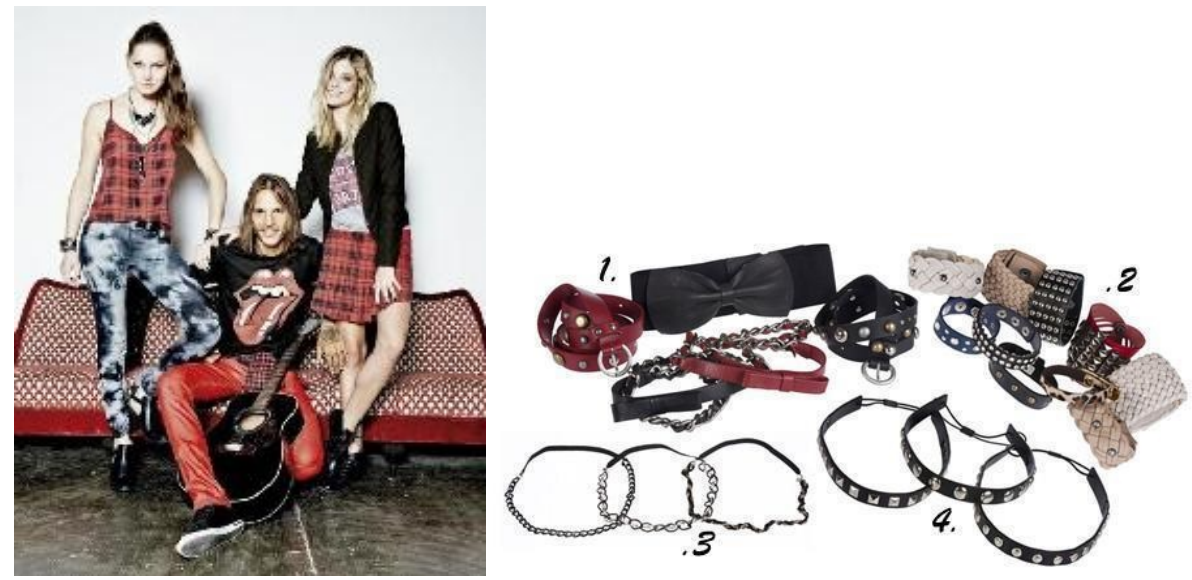

Figura 3. (direita) Editorial C\&A: “Na C\&A tem muito rock!”. (esquerda) Editorial C\&A: Isabeli Fontana, Acessórios 2013.

Fonte: http://www.lilianpacce.com.br/moda/rock-xadrez-cea/.

Fonte: http://capricho.abril.com.br/blogs/radarfashion/confira-a-colecao-girlierock-da-isabeli-fontana-paraca/

Ali estão as roupas em xadrez, rasgadas, desfiadas com estampas de bandas ou até mesmo, as que divulgam o feminismo, a proposta do uso de acessórios pesados, de couro, e rebites, e o retorno da estética do "faça você mesmo". Nestas novas aproximações se observam as influências tanto da estética do punk feminista, no "faça você mesmo", tanto pelas peças inspiradas nos grandes estilistas do estilo, como em um revival de sensações que passa a ser estampado nas lojas "de departamento" e para quem quiser "ter sua rebeldia" exibida a todos.

\section{CONSIDERAÇÕES FINAIS}

Esta pesquisa teve como finalidade relatar a identidade do movimento feminista punk Riot Grrrl - enquanto ativismo sociopolítico - com foco no seu histórico, lutas, e diversidade mecanismos informativos. O estilo riot se configurou como um mecanismo para transmitir, não só na cena underground, punk ou hardcore, o espaço do feminino. Disseminou ideias e ideais a partir de informações codificadas na indumentária, nas letras das músicas das bandas e das fanzines. Para o Movimento, o corpo feminino e a roupa são formas de discurso voltadas às discussões de gênero com fortes significados de revolta e na necessidade de emancipação dos estereótipos e da estética de comportamento da sociedade patriarcal. 
A investigação analisa um entre vários movimentos de contracultura que pode ser estudado a partir de suas expressões. Entre estas, a função da moda aparece como um espaço de discurso e, portanto, de informação.

Sendo assim, o diálogo da Biblioteconomia e para a Ciência da Informação com o campo da moda pode propiciar estudos voltados aos grupos e movimentos sociais e suas respectivas representações informativas. A ação interdisciplinar da Ciência da informação e da Biblioteconomia com a moda poderia se aprofundar, igualmente, no caráter prático nas relações humanas e na sua efetiva participação na interpretação de contextos sociais além daqueles definidos em estruturas textuais.

A estrutura simbólica da indumentária feminista das riots carrega significações sociais em um determinado contexto histórico, o qual é revisitado com objetivos distintos dos originais (apreensão pelas fast fashion, por exemplo), cuja representação informativa procura reproduzir os conceitos de rebeldia e do do yourself promovidos pelo movimento punk. Sendo assim, a interação e a relação interpessoal na vertente da moda como objeto de informação e do corpo como discurso permitiria uma discussão alinhada aos atos comunicativos, ao diálogo, e estes como propostas de emancipação nos quais o indivíduo cria valores e interage com o mundo e com o outro.

Embora este seja um estudo exploratório, o tema da moda e indumentária poderia vir a contribuir como um espaço para investigações relativas à informação e às linguagens visuais no contexto da Ciência da Informação e da Biblioteconomia. 


\section{REFERÊNCIAS}

Arruda, R. (2011). A música feminista das Riot Girls. Blogueiras feministas. Recuperado de http://blogueirasfeministas.com/2011/07/musica -feminista-riot-girls/

Bivar, A. (1982). O que é punk. São Paulo: Brasiliense.

Bortholuzzi, J. (2012). A relação entre a moda, o movimento punk e sua rainha, Vivienne Westwood. In Anais do 8. Colóquio de Moda. Rio de Janeiro. Recuperado de http://www.coloquiomoda.com.br/anais/anais/ 8-Coloquio-de-Moda_2012/GT06/COMUNICACAO-ORAL/ 102634_A_relacao_entre_a_moda_o_movimento_punk_e _sua_rainha_Vivienne_Westwood.pdf

Braga, J. (2004). História da moda: uma narrativa. São Paulo: Anhembi Morumbi.

Brandes, A. Z., \& Souza, P. (2012). Corpo e moda pela perspectiva do contemporâneo. Projetica, 3(1), 119-129.

Ciquini, F. H. (2010). Suave rebeldia: como a visualidade na moda contemporânea se apropria da estética do movimento punk (Dissertação do Mestrado em Comunicação). Universidade Estadual de Londrina.

Cláudio, I. (2009). O elegante feminismo de Coco Chanel. Isto É independente, 2085. Recuperado de http://www.terra .com.br/istoe-temp/edicoes/2085/imprime154614.htm

Coloni, D. A., \& Fernandes, C. A. (2005). A agressividade na indumentária punk e seu traje de oposição. In Anais do 1. Design, Arte, Moda e Tecnologia. São Paulo. Recuperado de http://www.coloquiomoda.com.br/anais/anais/ 1-Coloquio-de-Moda_2005/COMUNICACOES-A_F.pdf

Gil, A. C. (2002). Como elaborar projetos de pesquisa. São Paulo: Atlas.

Habermas, J. (1987). Teoría de la acción comunicativa (2a. ed.). Madrid: Taurus.

Iori, D., Menegazzi, D., Moraes, A., \& Richetti, J. (2006). Tribos urbanas: Punks. Advérbio, 5, 1-8.

Joaquim, J. T., \& Mesquita, C. (2012). Rupturas do vestir: articulações entre moda e feminismo. In Anais do 1. Design, Arte, Moda e Tecnologia (p. 15-58). São Paulo. Recuperado de http://sitios.anhembi.br/damt/arquivos/6.pdf

Lehmann, H. T. (2014). Esthetics of resistance, esthetics of revolt. Pitágoras, 500(6), 4-19. Recuperado de http://www.publionline.iar.unicamp.br/index.php/ pit500/article/view/185/180

Leite, F. L. (2012). Mídia e policia na (des) construção do movimento punk paulistano (Relatório Parcial de Pesquisa de Iniciação Cientifica). São Paulo: PUC-SP.

Marconi, M. A., \& Lakatos, E. M. (2006). Fundamentos da metodologia científica. São Paulo: Atlas.

Melo, E. I. (2006). Riot Grrrl: feminismo na cultura juvenil punk. In Anais do 7. Seminário Fazendo Gênero. Florianópolis: UFSC, UDESC. Recuperado de http://www.fazendogenero .ufsc.br/7/artigos/E/Erica_Melo_Riot_01.pdf

Miranda, S. (2006). Como as necessidades de informação podem se relacionar com as competências informacionais. Ciência da Informação, 35(3), 99-144. Recuperado em 15 ago. 2015, de http://dx.doi.org/10.1590/S0100 $-19652006000300010$

Monteiro, L. L. C., \& Garcia, L. G. (2013). Veganismo, feminismo e movimentos sociais no Brasil. In Anais do 10. Seminário Fazendo Gênero. Florianópolis: UFSC, UDESC.
Neira, L. (2008). A invenção da moda brasileira. Caligrama, 4(1). Recuperado de http://dx.doi.org/10.11606/issn.1808 -0820.cali.2008.68123

Oliveira, A. C., \& Castilho, K. (2008). Corpo e moda: por uma compreensão do contemporâneo. São Paulo: Estação das Letras e Cores.

Oliveira, M. (2005). Origens de evolução da Ciência da Informação. In M. Oliveira (Ed.), Ciência da Informação e Biblioteconomia: novos conteúdos e espaços de atuação (p. 11 - 71). Belo Horizonte: UFMG.

Ortega, C. D. (2006). Relações históricas entre Biblioteconomia, Documentação e Ciência da Informação. DataGramaZero: Revista de Ciência da Informação, 5(5). Recuperado em 15 ago. 2015, de http://dgz.org.br/out04/Art 03.htm

Piovesan, A. (1968). Da necessidade das escolas de saúde pública elaborarem métodos simplificados de investigação social (Faculdade de Saúde Pública da USP). Pontifícia Universidade Católica do Rio de Janeiro. Departamento de Administração.

Queiróz, M. I. (1992). O pesquisador, o problema da pesquisa, a escolha de técnicas: algumas reflexões. In A. B. S. G. Lang (Ed.), Reflexões sobre a pesquisa sociológica (p. 13-19).

Ribeiro, J. K., Costa, J. C., \& Santiago, I. M. (2012). Um jeito diferente e "novo" de ser feminista: em cena, o Riot Grrrl. Revista Ártemis, 5(13), 222-240. Recuperado em 15 ago. 2015, de http://periodicos.ufpb.br/ojs/index.php/artemis/article/ viewFile/14226/8154

Rocha, M. (2005). Punk na moda. Revista Cult, 96. Recuperado de http://revistacult.uol.com.br/home/2010/03/a-influencia -da-cultura-punk-no-vestuario-contemporaneo/

Souza, H., \& Fonseca, P. (2009). As tribos urbanas: as de ontem até às de hoje. Nascer e Crescer: revista do Hospital de Crianças Maria Pia, 18(3), 209-214. Recuperado em 15 ago. 2015, de http://repositorio.chporto.pt/bitstream/10400.16/ 1271/1/TribosUrbanas 18-3.pdf

Weber, A. F., Gallina, J. F., \& Ronsini, V. V. (2004). A construção do estilo punk: identidade, mídia e classe social. Cadernos de Comunicação, 10, 167-180. Recuperado em 15 ago. 2015, de http://cascavel.ufsm.br/revistas/ojs-2.2.2/ index.php/ccomunicacao/article/viewFile/5162/3171 (Jornada de Iniciação Cientifica da INTERCOM)

\section{Como citar este artigo (APA):}

Castro, K. L., Castro, J. L. \& Oliveira, A. N. (2015). A moda como objeto de informação: o caso do Movimento Feminista Punk Riot Grrrl. AtoZ: novas práticas em informação e conhecimento, 4(1), 24 - 33. Recuperado de: http://dx.doi.org/10.5380/atoz.v4i1.41762 